Technical Review Report for the Mound 1KW Package Safety Analysis Report for Packaging Addendum No. 1, through Revision b

A. DiSabatino, M. West, R. Hafner, E. Russell

October 9, 2007 
This document was prepared as an account of work sponsored by an agency of the United States government. Neither the United States government nor Lawrence Livermore National Security, LLC, nor any of their employees makes any warranty, expressed or implied, or assumes any legal liability or responsibility for the accuracy, completeness, or usefulness of any information, apparatus, product, or process disclosed, or represents that its use would not infringe privately owned rights. Reference herein to any specific commercial product, process, or service by trade name, trademark, manufacturer, or otherwise does not necessarily constitute or imply its endorsement, recommendation, or favoring by the United States government or Lawrence Livermore National Security, LLC. The views and opinions of authors expressed herein do not necessarily state or reflect those of the United States government or Lawrence Livermore National Security, LLC, and shall not be used for advertising or product endorsement purposes.

This work performed under the auspices of the U.S. Department of Energy by Lawrence Livermore National Laboratory under Contract DE-AC52-07NA27344. 


\section{Technical Review Report for the Mound 1KW Package Safety Analysis Report for Packaging Addendum No. 1, through Revision b R1033-0064-ES-00 Docket 07-04-9516}

June 4, 2007 


\section{$\underline{\text { Overview }}$}

This Technical Review Report (TRR) documents the review, performed by the Lawrence Livermore National Laboratory (LLNL) staff, at the request of the U.S. Department of Energy (DOE), on the Mound 1KW Package Safety Analysis Report for Packaging, Addendum No. 1, Revision $b$, dated May 2007 (Addendum 1) ${ }^{[1]}$. The Mound 1KW Package is certified by DOE Certificate of Compliance $(\mathrm{CoC})^{[2]}$ number USA/9516/B(U)F-85 for the transportation of Type B quantities of plutonium heat source material. The safety analysis of the package is documented in the Safety Analysis Report for Packaging (SARP) for the Mound 1KW Package (i.e., the Mound $1 \mathrm{KW}$ SARP, or the SARP) ${ }^{[3]}$.

Addendum $1^{[1]}$ incorporates a new fueled capsule assembly payload. The following changes have been made to add this payload:

1. The primary containment vessel (PCV) will be of the same design, but will increase in height to 11.16 in.;

2. A new graphite support block will be added to support up to three fueled capsule assemblies per package;

3. The cutting groove height on the secondary containment vessel (SCV) will be heightened to accommodate the taller PCV; and

4. A 3.38 in. high graphite filler block will be placed on top of the PCV.

All other packaging features, as described in the Mound $1 \mathrm{KW}$ SARP ${ }^{[3]}$, remain unchanged.

This report documents the LLNL review of Addendum $1^{[1]}$. The specific review for each SARP Chapter is documented herein. 


\section{Technical Review Report \\ for the \\ Mound 1KW Package SARP \\ Addendum No. 1, through Revision b}

\section{Chapter 1: General Information}

This section of the TRR covers the review of the General Information provided in Chapter 1 of Addendum $1^{[1]}$. The applicant requests the addition of the fueled capsule assembly payload as a new authorized contents for the SARP. This new payload is a variation of currently authorized payloads, and each $1 \mathrm{KW}$ package may be loaded with up to three fueled capsule assemblies. Addendum $1^{[1]}$ describes the fueled capsule assembly payload, using schematic and engineering drawings.

The new payload consists of the following major components:

1. The fueled capsule assembly,

2. A graphite support block for loading up to three fueled capsules inside the PCV, and

3. A graphite filler block, as a spacer within the SCV.

The fueled capsule assembly consists of granular plutonium dioxide fuel and a hollow spacer assembly seal welded within a primary fueled capsule assembly, that is, in turn, seal welded within a secondary capsule subassembly. The overall size of the fueled capsule assembly is 8.581 in. long, with an outside diameter of $1.670 \mathrm{in}$. The weight of the loaded SCV with three fueled capsule assemblies is $61 \mathrm{lb}$. The maximum decay heat is $166.7 \mathrm{~W}$ per fueled capsule assembly, or a maximum of $500 \mathrm{~W}$ total per package. The fueled capsule assembly plutonium dioxide isotopic composition is given in the table below. Note that the "other ${ }_{\Sigma} \mathrm{Pu}(\mathrm{wt} \%)$ " column should be updated to $4.0 \mathrm{wt} \%$ to be consistent with the information shown in the current version of the $\mathrm{CoC}^{[2]}$.

Plutonium Initial Isotopic Limits

\begin{tabular}{|l|c|c|c|c|c|c|c|c|}
\hline & $\begin{array}{c}{ }^{236} \mathrm{Pu} \\
(\mathrm{ppm})\end{array}$ & $\begin{array}{c}{ }^{238} \mathrm{Pu} \\
(\text { wt \%) }\end{array}$ & $\begin{array}{c}{ }^{239} \mathrm{Pu}+ \\
{ }^{241} \mathrm{Pu} \\
(\text { wt \%) }\end{array}$ & $\begin{array}{c}\text { other }{ }_{\Sigma} \mathrm{Pu} \\
(\text { wt \%) }\end{array}$ & $\begin{array}{c}{ }^{241} \mathrm{Am} \\
(\text { wt \%) }\end{array}$ & $\begin{array}{c}{ }^{237} \mathrm{~Np} \\
(\text { wt \%) }\end{array}$ & $\begin{array}{c}\mathrm{U} \\
(\text { wt \%) }\end{array}$ & $\begin{array}{c}{ }^{\mathrm{T} h} \\
(\text { wt \%) }\end{array}$ \\
\hline $\begin{array}{l}\text { Source } \\
\text { Specification }\end{array}$ & $\leq 2.0$ & $74-90$ & $\begin{array}{c}25.5- \\
8.4\end{array}$ & $\leq 2.3$ & $\leq 0.1$ & $\leq 1.0$ & $\leq 3.0$ & $\leq 0.5$ \\
\hline
\end{tabular}

\section{Findings}

Addendum $1^{[1]}$ has three fueled capsule assemblies (FCA) that contain granular plutonium dioxide. Each FCA is designed to have a maximum decay heat of $166.7 \mathrm{~W}$. With up to three FCAs per package, the complete package will have a maximum of $500 \mathrm{~W}$, total. 
Based on the review of the statements and representations in Addendum $1^{[1]}$, the staff has concluded that the design of the Mound $1 \mathrm{KW}$ package, with the loading configuration described in Addendum $1^{[1]}$, has been adequately demonstrated to meet the requirements of 10 CFR 71.

\section{Conditions of Approval}

Before the fueled capsule assembly can be added as new contents, an engineering drawing that describes the fueled capsule assembly payload overall configuration will have to be added to the drawing section of the existing $(\mathrm{CoC})^{[2]}$, and Table 1.2.3-1 of Addendum $1^{[1]}$ will have to be corrected as noted.

\section{Chapter 2: Structural Evaluation}

This section covers the assessment of the Structural Evaluation information provided in Chapter 2 of Addendum $1^{[1]}$.

\section{Findings}

In agreement with the SARP, the staff has determined that the new payload (i.e., up to three fueled capsule assemblies) will not significantly change the structural performance of the $1 \mathrm{KW}$ Package and its compliance with the requirements of 10 CFR 71. This determination is based on the following considerations:

1. All package components are unchanged except the PCV, graphite filler block, graphite support block, and the payload capsule;

2. The length of the PCV (11.6 in.) is increased from that (5 in.) of the existing standard $\mathrm{PCV}$, but the increase is insufficient to cause buckling concerns;

3. The weight (61 pounds including the SCV, PCV, graphite filler block, and graphite support block) and the thermal power $(500 \mathrm{~W})$ of the new payload are substantially the same as that of previously approved payloads;

4. The material of the payload capsule will not rupture, even at the high temperatures of the hypothetical accident fire conditions, as shown in the thermal evaluation in Chapter 3; and

5. There are no chemical/galvanic reactions between the capsule material and the materials of the PCV and the graphite support block in the expected thermal and radiation environments.

Consequently, no significant change in the structural performance of the package is expected due to this payload.

Therefore, based on the review of the statements and representations in Addendum $1^{[1]}$, the staff has concluded that the structural design for the proposed fueled capsule assembly payload has been adequately described and demonstrated to meet the requirements of 10 CFR 71 .

\section{Conditions of Approval}

The staff has also concluded that no additional structurally-related conditions of approval need to be added to the existing $\mathrm{CoC}^{[2]}$ for approval of this request. 


\section{Chapter 3: Thermal Evaluation}

This section covers the assessment of the Thermal Evaluation information provided in Chapter 3 of Addendum $1^{[1]}$.

\section{Findings}

In agreement with the SARP, the staff has determined that the new payload (i.e., up to three fueled capsule assemblies) will not significantly change the thermal performance of the $1 \mathrm{KW}$ Package and its compliance with the requirements of 10 CFR 71. This determination is based on the following considerations:

1. Under normal conditions of transport, the maximum temperature of the PCV, SCV and cask are below the temperature limit $\left(800^{\circ} \mathrm{F}\right)$ specified by ASME B\&PV Code, Section III, Subsection NB, Article NB-3000 on design criteria.

2. For hypothetical accident conditions, the Addendum $1^{[1]}$ analysis shows that the maximum temperature of the fueled capsule, the PCV and the SCV are above the temperature limit recommended by the ASME Code, but below the temperatures where creep rupture of the components is a concern. For the PCV and SCV, the combined thermal and structural loading results in stress intensities less than the ASME design stress intensity limits (with material properties evaluated at corresponding elevated temperatures). The favorable outcome is mainly attributed to the short duration of the fire condition.

3. Addendum $1^{[1]}$ also estimates the potential amount of helium released from the fueled capsule assemblies, and calculates the time to reach the maximum allowable pressure of the PCV (or the maximum fuel age at completion of shipments). The result, 75 months, is reported in Addendum $1^{[1]}$, Table 3.4.4-3, to limit the shipping duration.

Therefore, based on the review of the information, statements, and representations in Addendum $1^{[1]}$, the staff has concluded that the thermal design of the Mound 1KW Package, with the packaging configuration as described in Addendum $1^{[1]}$, has been adequately demonstrated to meet the requirements of 10 CFR 71 .

\section{Conditions of Approval}

The staff recommends that the information in Addendum $1^{[1]}$, Table 3.4.4-3, be incorporated into the SARP, in Table 3.17.

\section{Chapter 4: Containment Evaluation}

This section covers the assessment of the Containment Evaluation information provided in Chapter 4 of Addendum $1^{[1]}$.

\section{Findings}

The Mound 1KW Package was originally certified under the requirements of 10 CFR 71 $(1983),{ }^{[4]}$ and later recertified under the requirements of 10 CFR 71 (1996). ${ }^{[5]}$ As a consequence, the Mound 1KW Package includes a double-containment system, as was required by the earlier regulatory requirements for plutonium oxide shipments. Since the applicant has not requested any relief from the double-containment requirements of 10 CFR 71.63 (1983) and/or 10 CFR 71.63 (1996), the older, double-containment requirements for plutonium oxide 
shipments are still applicable. Since the addition of the fueled capsule assembly payload does nothing to change the situation, the staff has concluded that the containment design has been adequately described to meet the requirements of 10 CFR 71.

\section{Conditions of Approval}

Based on the review of the statements and representations in Addendum $1^{[1]}$, the staff has concluded that the package design with the fueled capsule assembly contents has been adequately described to meet the requirements of 10 CFR 71 . The staff has, therefore, concluded that no additional containment-related conditions of approval need to be added to the existing $\mathrm{CoC}^{[2]}$ for the approval of this request.

\section{Chapter 5: Shielding Evaluation}

This section covers the assessment of the Shielding Evaluation information provided in Chapter 5 of Addendum $1^{[1]}$.

\section{Findings}

Addendum $1^{[1]}$ sets forth reasons that the shielding analyses performed as part of the Mound $1 \mathrm{KW}$ SARP remain bounding for the payload in this addendum. The original payloads generate up to $936 \mathrm{~W}$ of decay heat, while the new limit is $500 \mathrm{~W}$, which is applicable to this addendum. In addition to this decrease in decay heat limit and the corresponding lower mass in this payload, the lower limit of the ${ }^{238} \mathrm{Pu}$ concentration in this addendum goes down from $79.5 \%$ to $74 \%$ with the upper limit remaining at $90 \%$.

Addendum $1^{[1]}$ presents arguments that both the neutron and gamma source terms would remain bounded by the original source terms in the SARP analyses with this change in the lower limit of ${ }^{238} \mathrm{Pu}$. In the case of the neutron source term, Addendum $1^{[1]}$ compared the subcritical multiplication of the $74 \%$ case to that in the $79.5 \%$ case, resulting in a factor of 1.03 or a $3 \%$ increase in the neutron source for the $74 \%$ case. This increase is more than offset by a decrease in the spontaneous fission and $(\alpha, n)$ production decrease for the $74 \%{ }^{238} \mathrm{Pu}$ case, amounting to $7 \%$. Thus, there is an overall reduction in the neutron source term by $4 \%$.

The staff has independently verified these arguments and concluded that the original SARP shielding analyses adequately bound this payload, and that the package meets the external radiation requirements of 10 CFR 71 .

\section{Conditions of Approval}

Based on the review of the statements and representations in Addendum $1^{[1]}$, the staff has concluded that the package design with the fueled capsule assembly payload has been adequately described to meet the requirements of $10 \mathrm{CFR} 71$. The staff has, therefore, concluded that no additional shielding-related conditions of approval need to be added to the existing $\mathrm{CoC}^{[2]}$ for the approval of this request.

\section{Chapter 6: Criticality Evaluation}

This section covers the assessment of the Criticality Evaluation information provided in Chapter 6 of Addendum $1^{[1]}$. 


\section{Findings}

Addendum $1^{[1]}$ did not provide criticality analyses based on contents and configuration consistent with the package under consideration in Addendum $1^{[1]}$ to the Mound 1KW SARP. The analyses were based on the eight product-can configuration in the SARP that contained 2,100 $\mathrm{g}$ of $\mathrm{PuO}_{2}$ compared with a maximum of $1,114.5 \mathrm{~g}$ of $\mathrm{PuO}_{2}$ in this package. The decrease in the lower limit of the ${ }^{238} \mathrm{Pu}$ concentration from $79.5 \%$ to $74 \%$ would result in a corresponding increase in the fissile isotope $\left({ }^{239} \mathrm{Pu} /{ }^{241} \mathrm{Pu}\right)$ content. Addendum $1^{[1]}$ provides results from the analyses of a single package with and without in-leakage of water and a $30-\mathrm{cm}$ water reflector surrounding the package, as well as an infinite array with and without interspersed water with $74 \%{ }^{238} \mathrm{Pu}$. It also provides the infinite array results for $79.5 \%$ and $90 \%{ }^{238} \mathrm{Pu}$ contents. All these calculations were performed with the eight product-can model, and demonstrated that the limiting multiplication factor was well below the Upper Subcritical Limit of 0.7 presented in Addendum $1^{[1]}$.

However, since Addendum $1^{[1]}$ did not model the package under consideration, the staff developed a model based on the actual package and performed a series of criticality calculations. Given that the CSI is 0 for this package, the staff modeled only the infinite arrays configurations. Since Addendum ${ }^{[1]}$ used a 2,100 g payload based on the eight-product can contents, the staff performed calculations with the $74 \%$ and $79.5 \%{ }^{238} \mathrm{Pu}$ content and a payload of $2,100 \mathrm{~g}$ of $\mathrm{PuO}_{2}$, in order to compare the results with those in Addendum $1^{[1]}$. The $74 \%$ case resulted in a $\mathrm{k}_{\infty}$ value of 0.5130 (compared to $0.5016[0.4994+2 \sigma]$ in Addendum $1^{[1]}$ ), and the $79.5 \%$ case resulted in a $\mathrm{k}_{\infty}$ value of 0.4868 (compared to $0.4873[0.4847+2 \sigma]$ in Addendum $1^{[1]}$ ). In addition to the cases with $2,100 \mathrm{~g}$, the staff performed calculations with the actual content of $1,114.5 \mathrm{~g}(371.5 \mathrm{~g}$ in each of the three capsules) of $\mathrm{PuO}_{2}$ and a composition consistent with the $74 \%$ and the $79.5 \%$

${ }^{238} \mathrm{Pu}$ content. These two calculations produced $\mathrm{k}_{\infty}$ values of 0.3597 and 0.3445 , respectively, demonstrating that an infinite array has a large margin of safety. Based on the results from the actual payload, the sub-critical multiplication factor change would be an increase of $2 \%$ for the $74 \%$ case. This number is smaller than the factor of $3 \%$ used in the neutron source term calculation in Chapter 5, confirming the adequacy of the arguments presented there (see Chapter 5 of this TRR).

Based on the above discussion, the staff has concluded that the Mound 1KW Package with the three fueled capsule assemblies can be shipped with a CSI of 0 .

\section{Conditions of Approval}

Based on the review of the statements and representations in Addendum $1^{[1]}$, the staff notes that criticality safety analyses are normally performed with the actual geometry and contents, a condition that was not met in this submittal. The staff also notes that the confirmatory analyses performed demonstrated that there was an adequate margin of safety for this package. Therefore, the staff has concluded that the package design with the fueled capsule assembly payload meets the criticality safety requirements of 10 CFR 71, and that no additional criticality-related conditions of approval need to be added to the existing $\mathrm{CoC}^{[2]}$ for the approval of this request.

\section{Chapter 7: Operating Procedures Review}

This section covers the assessment of the Operating Procedures information provided in Chapter 7 of Addendum $1^{[1]}$. 


\section{Findings}

Based on the review of the statements and representations in Addendum $1^{[1]}$, the staff has concluded that the Operating Procedures for the $1 \mathrm{KW}$ Package, with the fueled capsule assembly payload, have been adequately described to meet the requirements of 10 CFR 71 .

\section{Conditions of Approval}

Based on the review of the statements and representations in Addendum $1^{[1]}$, the staff has concluded that the package design with the fueled capsule assembly payload has been adequately described to meet the requirements of 10 CFR 71. The information included in Table 7-1 of Addendum $1^{[1]}$ should be included in Table 7.1 of the $1 \mathrm{KW}$ SARP, since the requirements specified in Chapter 7 of the SARP are explicitly included in the existing $\mathrm{CoC}^{[2]}$, as pre-existing Conditions of Approval.

\section{Chapter 8: Acceptance Tests and Maintenance Program Review}

This section covers the assessment of the Acceptance Tests and Maintenance Program information provided in Chapter 8 of Addendum $1^{[1]}$.

\section{Findings}

Based on the review of the statements and representations in Addendum $1^{[1]}$, the staff has concluded that the Acceptance Tests and Maintenance Program for the 1KW Package, with the fueled capsule assembly payload, has been adequately described to meet the requirements of 10 CFR 71. The staff has also concluded, however, that there is no evidence to suggest, in either Addendum ${ }^{[1]}$, or Revision $7 \mathrm{c}$ of the $1 \mathrm{KW}$ SARP ${ }^{[3]}$, that the external markings of the packaging have been updated to meet the requirements specified in 49 CFR $172.310(\mathrm{~d})^{[6]}$.

\section{Conditions of Approval}

Based on the review of the statements and representations in Addendum $1^{[1]}$, the staff has concluded that the 1KW Package design, with the fueled capsule assembly payload, has been adequately described to meet the requirements of 10 CFR 71. However, as was noted above, neither Addendum $1^{[1]}$, nor Revision $7 \mathrm{c}$ of the $1 \mathrm{KW} \mathrm{SARP}{ }^{[3]}$, shows that the external markings of the packaging have been updated to meet the requirements specified in 49 CFR $172.310(\mathrm{~d})^{[6]}$. Evidence that the external markings of the packaging have been updated to meet the requirements of 49 CFR $172.310(\mathrm{~d}){ }^{[6]}$ will, therefore, have to be provided to the Headquarters Certifying Official before the approval of this request can be granted.

\section{Chapter 9: Quality Assurance Review}

This section covers the assessment of the Quality Assurance information provided in Chapter 9 of the Addendum $1^{[1]}$.

\section{Findings}

Chapter 9 of Addendum $1^{[1]}$ utilizes Chapter 9 of the Mound 1KW SARP ${ }^{[3]}$ without change. The components described in Addendum $1^{[1]}$ (i.e., PCV, graphite spacer, and filler blocks) are adequately covered by the Q-list in the existing SARP; however, the component descriptions do not agree exactly with the Q-list descriptions. In the Addendum, the components should be the 
PCV, the graphite support block, and the graphite filler block. Also, in referring the reader to the Quality Assurance Plan described in Chapter 9 of the Mound 1KW SARP, Addendum $1^{[1]}$ does not clarify that the name, Duratek Federal Services has been changed to Energy Solutions Federal Services.

Based on a review of the statements and representations in the current submittal, the staff concludes that the Quality Assurance program has been adequately described, and meets the quality assurance requirements of Subpart H of 10 CFR 71. Package-specific requirements are adequate to assure the package is designed, fabricated, assembled, tested, used, maintained, modified, and repaired in a manner consistent with its evaluation.

\section{Conditions of Approval}

Based on the review of the statements and representations in the current submittal, the staff has concluded that the quality assurance program has been adequately described to meet the requirements of $10 \mathrm{CFR} 71$. The staff has also concluded that no additional quality assurancerelated conditions of approval need to be added to the existing $\mathrm{CoC}^{[2]}$ for the approval of this request.

\section{References}

[1] Mound 1KW Package Safety Analysis Report for Packaging, Addendum No. 1, Revision b, R1033-0064-ES-00, May 2007.

[2] U.S. Department of Energy Certificate of Compliance, USA/9516/B (U) F-85 (DOE), Revision 12, February 2006.

[3] Safety Analysis Report for Packaging for the Mound 1KW Package, USA/9516/B(U)F-85 (DOE), MLM-MU-91-64-001, Revision 7c, February 2006.

[4] Title 10-Energy, Chapter I-Nuclear Regulatory Commission, "Final Rule: 10 CFR Part 71Packaging of Radioactive Material for Transportation and Transportation of Radioactive Material Under Certain Conditions; Compatibility with IAEA Regulations," 48 F.R. 35600, pp. 35600 35627, August 5, 1983.

[5] Nuclear Regulatory Commission, 10 CFR Part 71, "Compatibility with International Atomic Energy Agency (IAEA), Final Rule,” 60 F.R. 50248, pp. 50248-50289, September 28, 1995.

[6] Department of Transportation, 49 CFR Parts 171, 172, 173, 174, 175, 176, 177 and 178, "Hazardous Materials Regulations; Compatibility with the Regulations of the International Atomic Energy Agency,” Final Rule, 69 F.R. 3632, pp. 3632-3697, January 26, 2004. 